\title{
Digital simulation and analysis of six modes of operation of BLDC motor drives using hysteresis band PWM switching scheme
}

\author{
Mohd Tariq ${ }^{1,2, *}$, Nidhi Varshney ${ }^{3}$ \\ ${ }^{1}$ Former Scientist, National Institute of Ocean Technology, Ministry of Earth Sciences, Govt. of India, Chennai, 600100 India \\ ${ }^{2}$ Presently working at Department of Electrical Engineering, Maulana Azad National Institute of Technology, Bhopal, 462051 India \\ ${ }^{3}$ Deep Sea Technology, National Institute of Ocean Technology, Ministry of Earth Sciences, Govt. of India, Chennai, 600100 India
}

\section{Email address:}

tariq.iitkgp@gmail.com (M. Tariq)

\section{To cite this article:}

Mohd Tariq, Nidhi Varshney. Digital Simulation and Analysis of Six Modes of Operation of BLDC Motor Drives Using Hysteresis Band PWM Switching Scheme. International Journal of Energy and Power Engineering. Vol. 3, No. 2, 2014, pp. 57-64.

doi: 10.11648/j.ijepe.20140302.14

\begin{abstract}
Permanent magnet Brushless DC (BLDC) motors are gaining popularity mainly because of their better characteristics and performance in comparison to other electrical motors. BLDC motors are generally controlled using a three phase power semiconductor bridge. For starting and providing proper commutation sequence to turn on the power devices in the inverter bridge, the rotor position sensors are required. Based on the rotor position, the power devices are commutated sequentially every 60 degrees. This paper presents MATLAB/SIMULINK based simulation of BLDC motor drives. BLDC motor drive operates in six modes for one complete revolution of the rotor. The complete analysis of six modes of operation with position of rotor has been presented in this paper. The switching of the IGBT switches and corresponding phase currents and line voltages are shown here for each sequence. The presented BLDC motor drive is based on hysteresis band PWM current controller for generating modulated switching signals.
\end{abstract}

Keywords: Brushless DC (BLDC) motor, MATLAB/SIMULINK, IGBT, hysteresis band, PWM, Current Controller

\section{Introduction}

Brushless DC electric motor also known as electronically commutated motors (ECMs) are synchronous motors. They are powered by a DC electric source via an integrated inverter. An integrated inverter produces an $\mathrm{AC}$ electric signal to drive the motor.

A typical brushless motor has a fixed armature and a rotating permanent magnet, thus eliminating problems associated with connecting current carrying coil to the moving armature. An electronic controller replaces the brush assembly of the brushed DC motor, which continually switches the phase to the windings to keep the motor turning. The controller performs the same work as performed by brushes by using a power electronic circuit (i.e. switching devices) rather than the brush system.

Brushless motors offer several advantages over brushed DC motors, including increased reliability, more torque per weight, more torque per watt (increased efficiency), reduced noise, longer lifetime as mechanical friction is not there (no brush and commutator erosion), etc. With no windings on the rotor, centrifugal forces are absent. Moreover the windings are supported by the housing hence they can be cooled by conduction, requiring no airflow inside the motor for cooling. This in turn means that the motor's internals can be entirely enclosed and protected from dirt or other foreign particle [1]-[3].

The key to BLDC commutation is to sense the rotor position, then energize the phases that will produce the maximum torque. The simplest way to know the correct moment to commutate the winding currents is by means of a position sensor. Most of the BLDC motor manufacturers supply motors with a three-element Hall effect position sensor. Each sensor element outputs a digital low level for 180 electrical degrees of electrical rotation, and a high level for the other 180 electrical degrees. The three sensors are offset from each other by 60 electrical degrees so that each sensor output is in alignment with one of the electromagnetic circuits [4] - [6]. A timing diagram showing the relationship between the hall sensor outputs 
and the back emf voltages is shown in Figure 1.

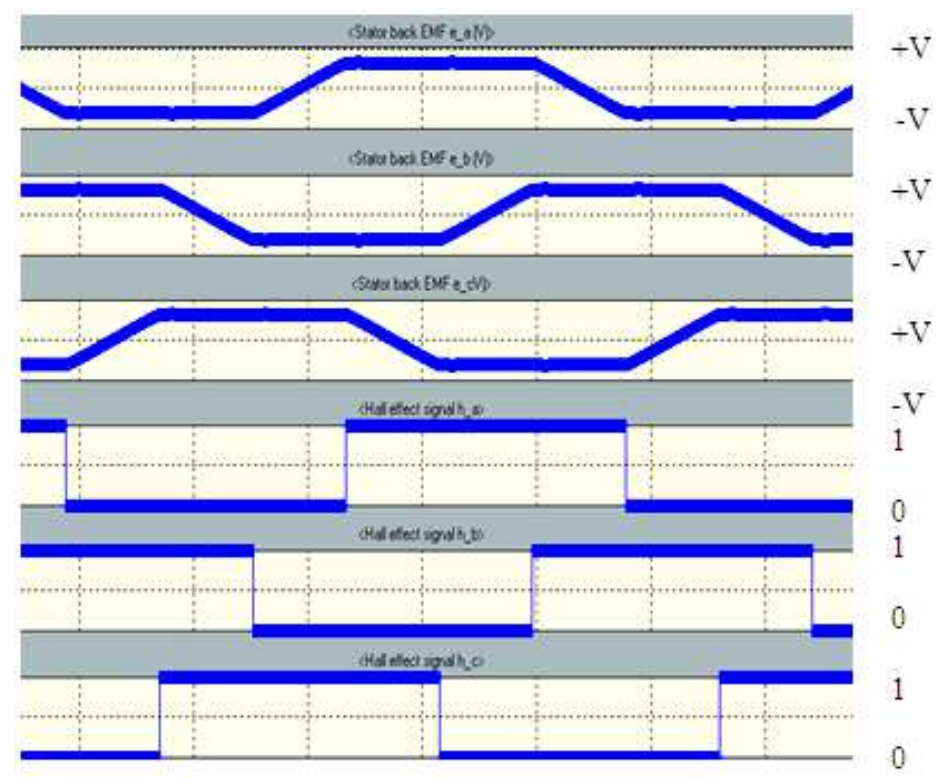

Figure 1. Relationship between hall sensor outputs and back emf voltages

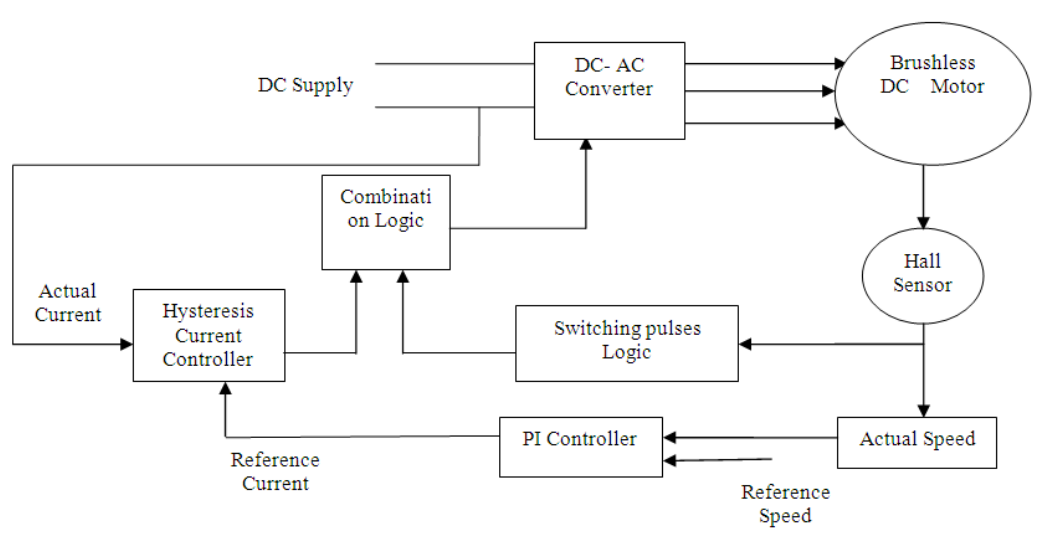

Figure 2. Block Diagram showing a BLDC Motor Drive System

A three phase BLDC motor has three phase winding on the stator and a permanent magnet rotor. The BLDC motor modeling is very similar to the standard wound rotor synchronous machine except that the BLDC motor has no damper windings and field excitation is provided by a permanent magnet rotor [7]-[8].

Much research has been done on the modeling and analysis of Brushless DC motor and many application note has been prepared by industries regarding working of BLDC motor [9]-[17]. However a comprehensive study which includes modeling, analysis and explanation of each of the six modes of operation of BLDC motor has not been found in literature. Moreover a study which shows the analysis for stator voltages and stator currents for each mode of operation is also missing in the literature.

In this paper a comprehensive study has been presented, which includes modeling and simulation of the BLDC motor, analysis of each of the six modes with the exact position of rotor and the corresponding stator voltages and currents. The presented study will help the researchers in the field of control of BLDC motor to understand its operation in a much better way.

In this paper hysteresis current controller based on a fixed hysteresis band is also used to generate pulse width modulated signals for the switching of inverter. Hysteresis current controller will maintain the actual currents flowing into the motor as close as possible to the rectangular reference values.

\section{Mathematical Modeling}

A three phase BLDC motor equation can be represented as:-

$$
\begin{aligned}
& v_{a}=i_{a} \cdot R_{a}+L_{a} \frac{d i_{a}}{d t}+M_{a b} \frac{d i_{b}}{d t}+M_{a c} \frac{d i_{c}}{d t}+e_{a} \\
& v_{b}=i_{b} \cdot R_{b}+L_{b} \frac{d i_{a}}{d t}+M_{b a} \frac{d i_{a}}{d t}+M_{b c} \frac{d i_{c}}{d t}+e_{b}
\end{aligned}
$$




$$
v_{c}=i_{c} \cdot R_{c}+L_{c} \frac{d i_{c}}{d t}+M_{c a} \frac{d i_{a}}{d t}+M_{c b} \frac{d i_{b}}{d t}+e_{c}
$$

Where

$\mathrm{R}$ : Stator resistance per phase, assumed to be equal for all phases

M: Mutual inductance between the phases.

ea, eb , ec : Back EMF of phase a , b and c respectively

$\mathrm{La}, \mathrm{Lb}$, Lc: Self inductance of phase $\mathrm{a}, \mathrm{b}$ and $\mathrm{c}$ respectively

The MATLAB/SIMULINK model based on mathematical equations $1-3$ was modeled.

\section{BLDC Motor Drive System}

A BLDC motor drive system is shown in figure 2. The drive consists of PI speed controller, hysteresis current controller, the motor and IGBT inverter. The measured speed of the motor after comparison with reference speed and an error was generated to be passed through proportional- integral (PI) controller for corrective action. The reference torque i.e. the output of PI controller will generate the reference current. The reference current after comparison with actual current will produce a pulse width modulated signal having a hysteresis band of $5 \%$. To generate switching commands the output of the hysteresis controller is given to the AND logic where it is AND with the switching signal for IGBT.

\section{Hysteresis Band PWM Switching Scheme}

The switching signals for the IGBTs of inverter were generated by hysteresis current controller. In Hysteresisband PWM actual current always tracks the reference current within a pre set hysteresis-band. As the current exceeds lower band limit the switching signal will be one (high) and as the current exceeds the higher band limit the switching signal will be zero (low). This can be observed from figure 3 .

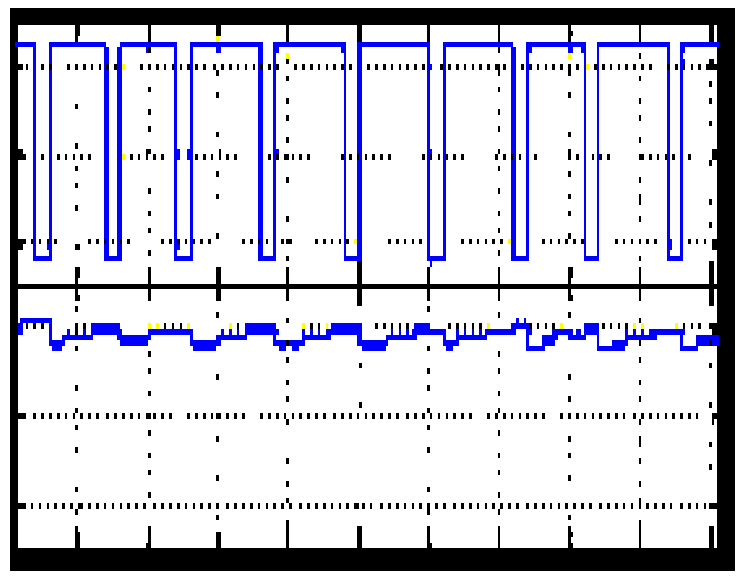

Figure 3. Generation of Switching Pulses by Hysteresis Band PWM

\section{Analysis of Six Modes of Operation}

The conversion of a dc power into an ac power at a desired output voltage and frequency is called inversion. For low and medium power inverters, gate -controlled turnoff devices (gate commutation devices), such as power BJT, IGBT, MOSFET, GTO, etc., are used [18].

Voltage source inverter (VSI) is fed by a DC source having small internal impedance. If one sees from the ac side, then the terminal voltage remains constant irrespective of the load current drawn.

A three phase inverter can be formed by connecting three single phase bridge inverters in parallel. Such a system requires twelve switch- diode pairs and three single-phase transformers. Whereas, a single three phase inverter unit consists of six switching devices and six diodes. A three phase inverter is classified as $180^{\circ}$ conduction or $120^{\circ}$ conduction modes inverter, according to the period of conduction of each switch.

In $120^{\circ}$ conduction mode each switch will conduct for 120 degree. So at a time only two switches will be ON, one from the top switches and another from the bottom switches

Figure 4 shows an IGBT based three phase inverter which was used in the presented simulation of BLDC motor drive. It consists of six switches with two switches in each leg. Each IGBT is having an anti parallel diode. It operates in 1200 conduction mode. This means switching modes will be Q6-Q1, Q1-Q2, Q2-Q3, Q3-Q4, Q4-Q5, Q5-Q6 and then again Q6-Q1.

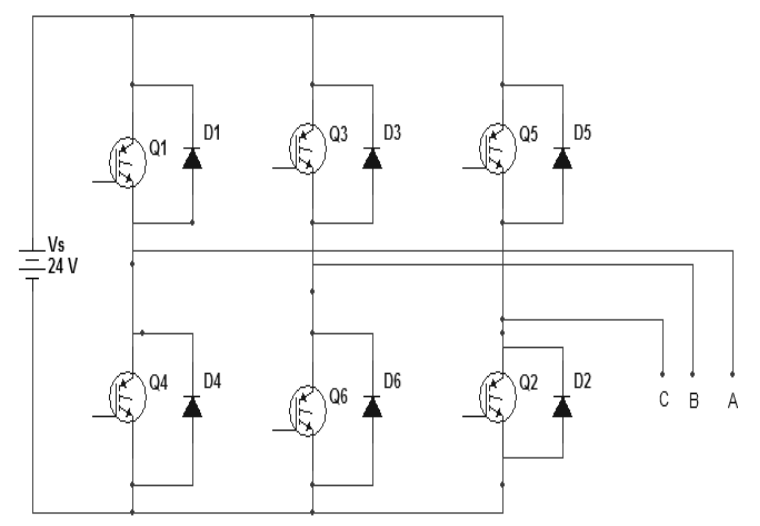

Figure 4. A three phase IGBT Inverter.(Operation $120^{\circ}$ Conduction mode)

BLDC motor drive operates in six modes for one complete revolution of the rotor. The switching of the IGBT switches and corresponding currents \& voltages are shown here for each sequence. Each mode is discussed here in details.

Mode 1: This mode corresponds to the hall sensor signal $\left[\begin{array}{lll}1 & 0 & 0\end{array}\right]$. In this, Phase A and Phase B will conduct while Phase $\mathrm{C}$ will be off. The IGBT switches [Q1 and Q6] will be on when the hysteresis controller will give switching commands and when the IGBT switches are off then the current will find alternate path through diode (D3 and D4). The line voltage $\mathrm{Vab}=+24$. The results can be 
observed from figure $5(\mathrm{a}), 5(\mathrm{~b})$ and $5(\mathrm{c})$.

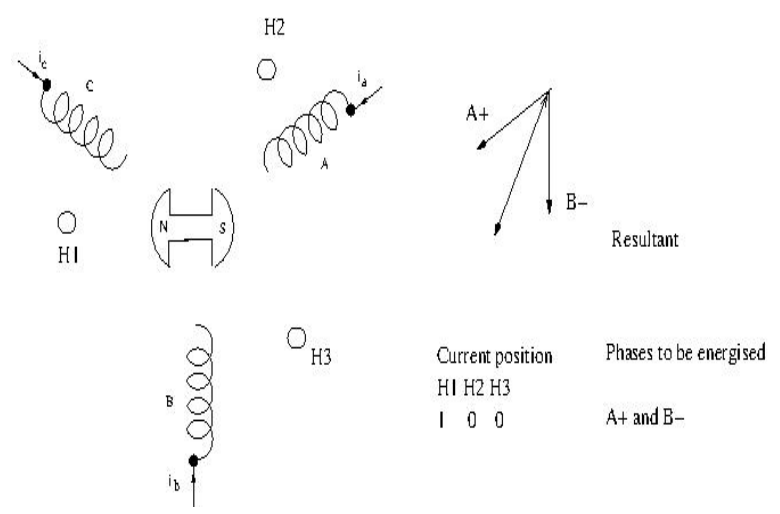

Figure 5 (a).Rotor and Stator Magnetic Field Position in Mode 1

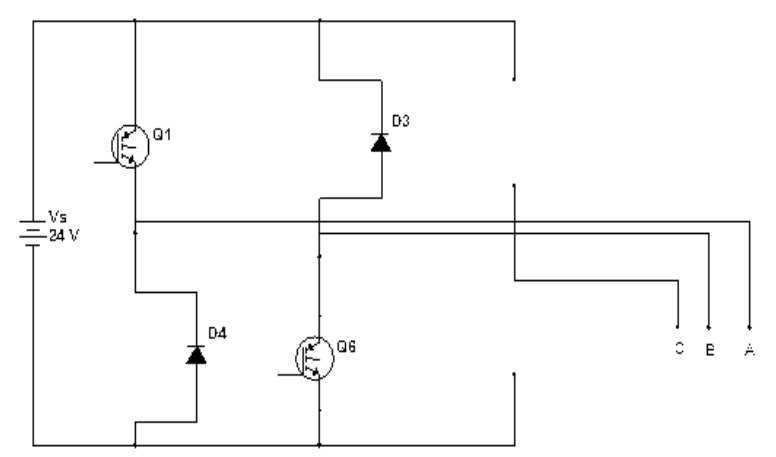

Figure 5 (b).Inverter Switches for Mode 1

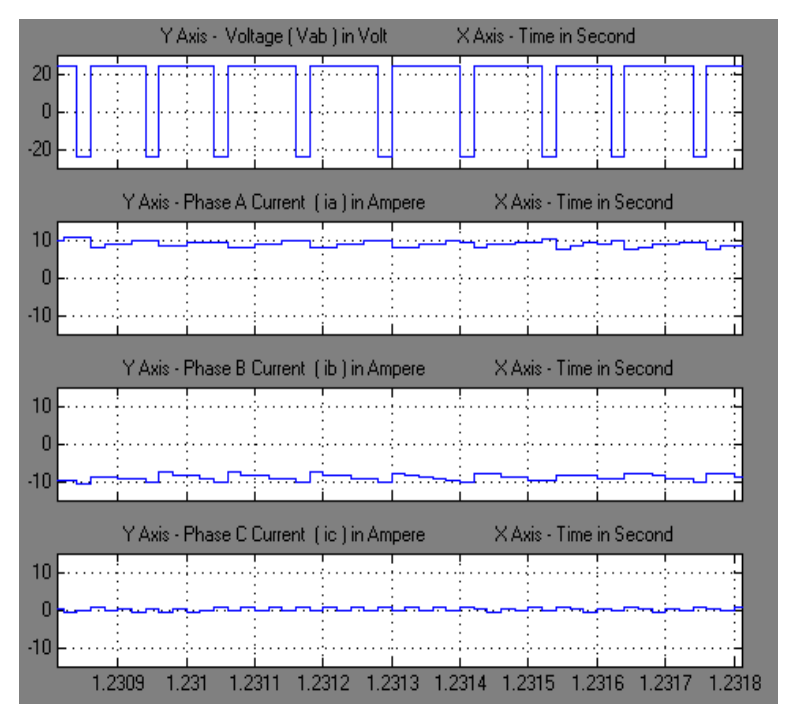

Figure 5 (c). Voltage (Vab) and current waveform (ia, ib, ic)

Mode 2: This mode corresponds to the hall sensor signal $\left[\begin{array}{lll}1 & 0 & 1\end{array}\right]$. In this, Phase $B$ and Phase $C$ will conduct while Phase A will be off. The IGBT switches [Q5 and Q6] will be on when the hysteresis controller will give switching commands and when the IGBT switches are off then the current will find alternate path through diode (D2 and D3). The line voltage $\mathrm{Vcb}=+24$. The results can be observed from figure 6 (a), $6(\mathrm{~b})$ and 6 (c).

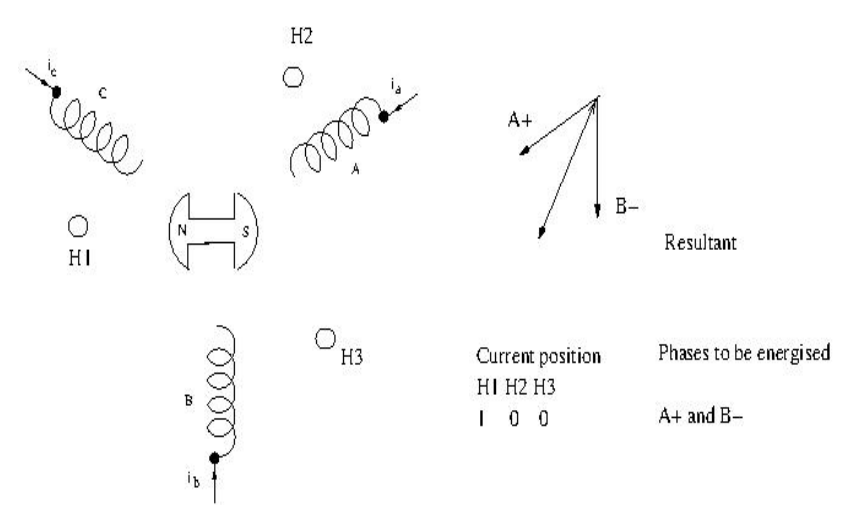

Figure 6 (a).Rotor and Stator Magnetic Field Position in Mode 2

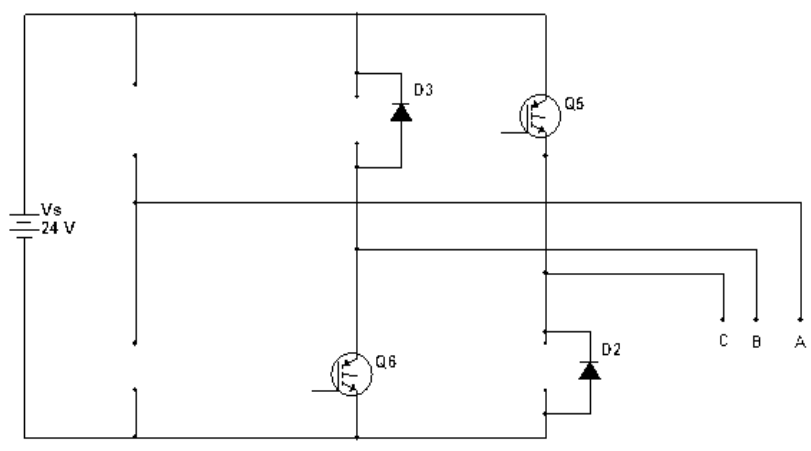

Figure 6 (b).Inverter Switches for Mode 2

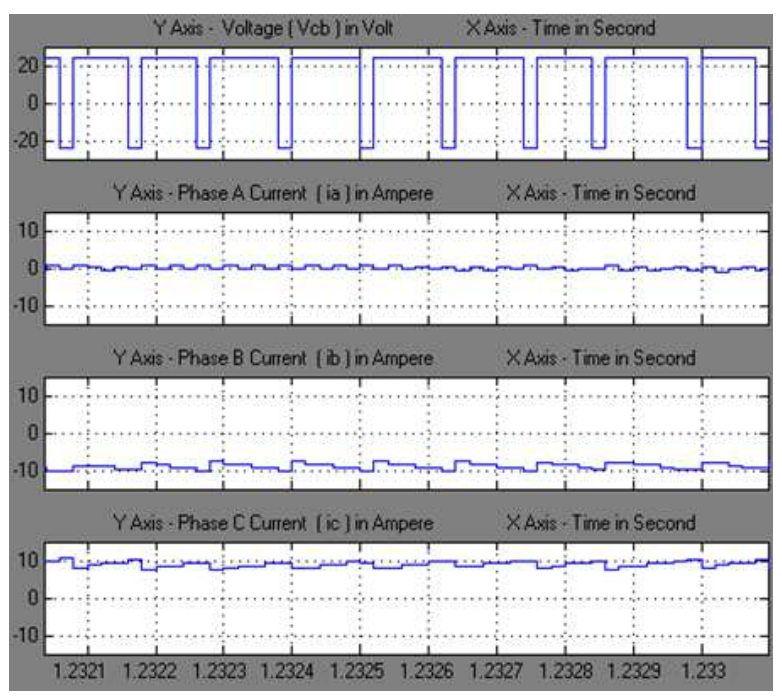

Figure 6 (c). Voltage (Vcb) and current waveform (ia, ib, ic)

Mode 3: This mode corresponds to the hall sensor signal $\left[\begin{array}{lll}0 & 0 & 1\end{array}\right]$. In this, Phase $A$ and Phase $C$ will conduct while Phase B will be off. The IGBT switches [Q4 and Q5] will be on when the hysteresis controller will give switching commands and when the IGBT switches are off then the current will find alternate path through diode (D1 and D2). The line voltage $\mathrm{Vca}=+24$. The results can be observed from figure 7 (a), 7(b) and 7 (c). 


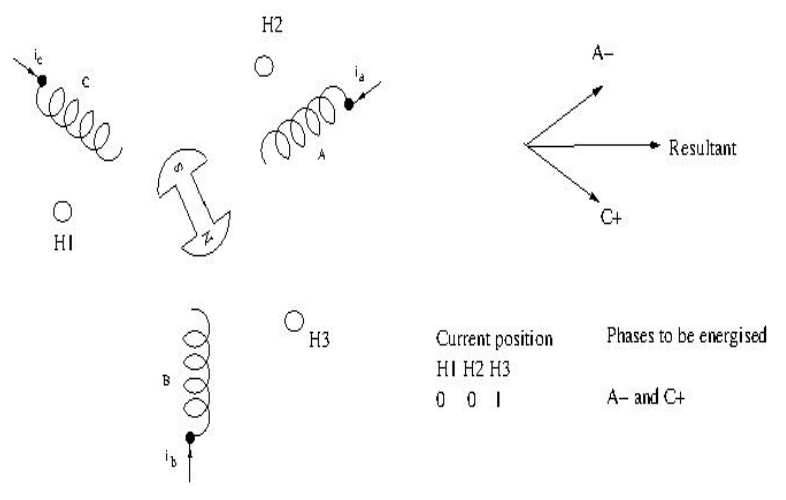

Figure 7 (a).Rotor and Stator Magnetic Field Position in Mode 3

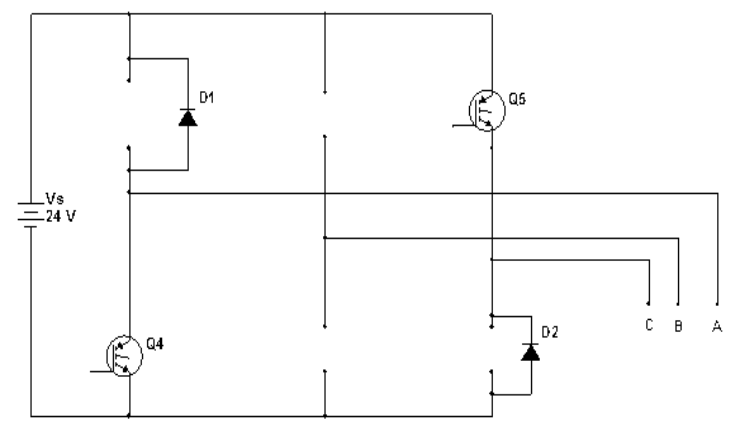

Figure 7 (b).Inverter Switches for Mode 3

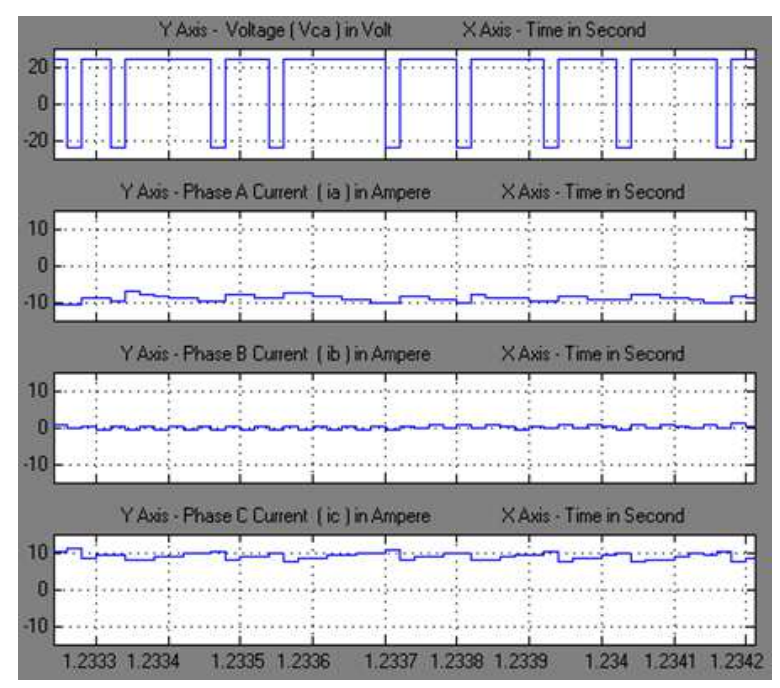

Figure 7 (c). Voltage (Vca) and current waveform (ia, ib, ic)

Mode 4: This mode corresponds to the hall sensor signal $\left[\begin{array}{lll}0 & 1 & 1\end{array}\right]$. In this, Phase A and Phase B will conduct while Phase $\mathrm{C}$ will be off. The IGBT switches [Q3 and Q4] will be on when the hysteresis controller will give switching commands and when the IGBT switches are off then the current will find alternate path through diode (D1 and D3). The line voltage $\mathrm{Vba}=+24$. The results can be observed from figure 8 (a), 8 (b) and 8 (c).

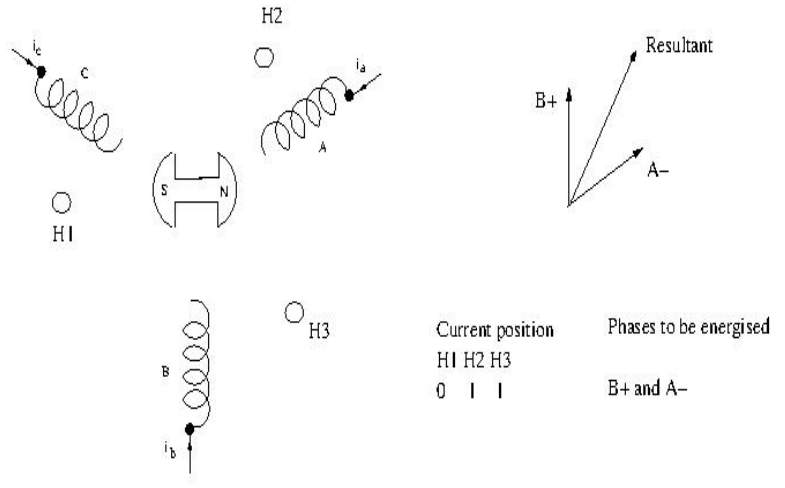

Figure 8 (a).Rotor and Stator Magnetic Field Position in Mode 4

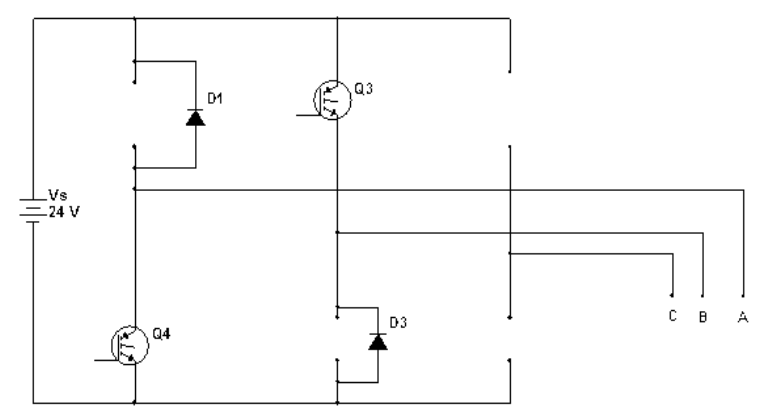

Figure 8 (b).Inverter Switches for Mode 4

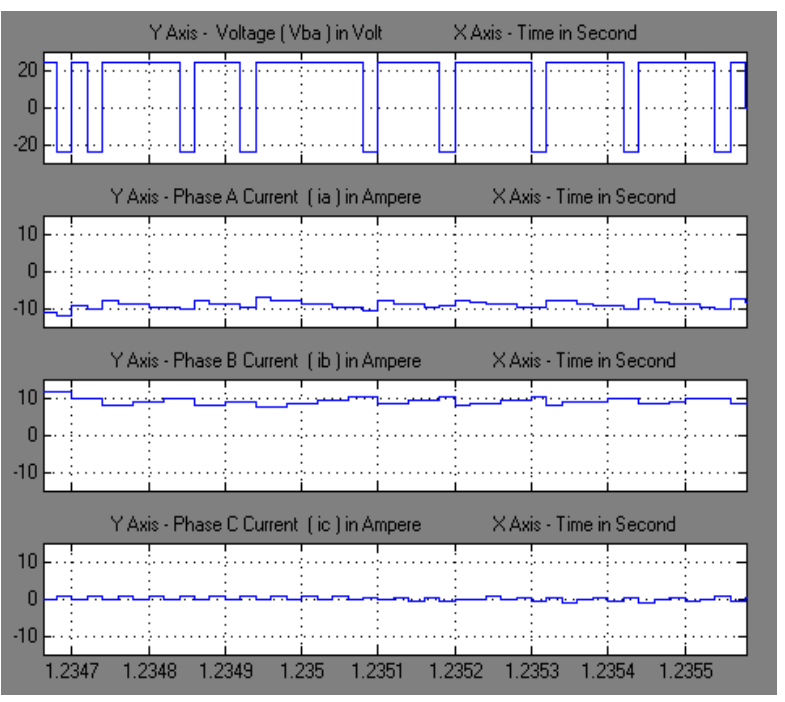

Figure 8 (c). Voltage (Vba) and current waveform (ia, ib, ic)

Mode 5: This mode corresponds to the hall sensor signal $\left[\begin{array}{lll}0 & 1 & 0\end{array}\right]$. In this, Phase $B$ and Phase $C$ will conduct while Phase A will be off. The IGBT switches [Q2 and Q3] will be on when the hysteresis controller will give switching commands and when the IGBT switches are off then the current will find alternate path through diode (D5 and D6). The line voltage $\mathrm{V}_{\mathrm{bc}}=+24$. The results can be observed from figure 9 (a), 9 (b) and 9 (c). 


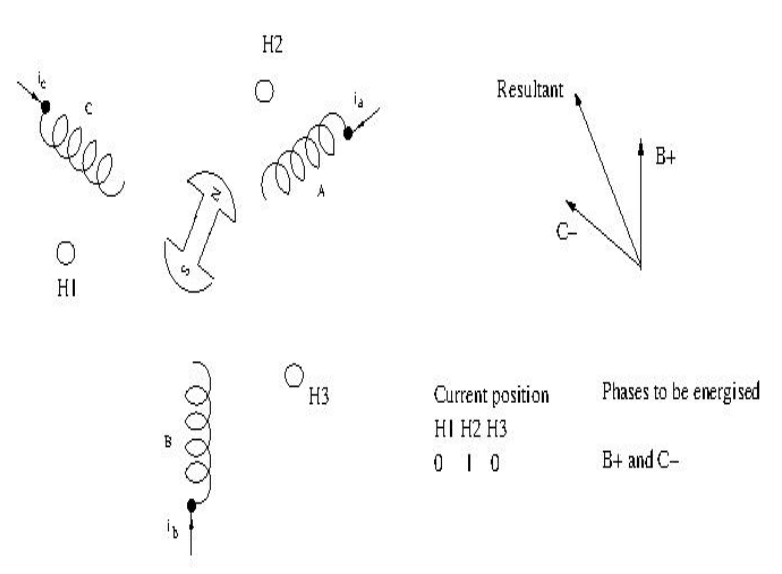

Figure 9 (a).Rotor and Stator Magnetic Field Position in Mode 5

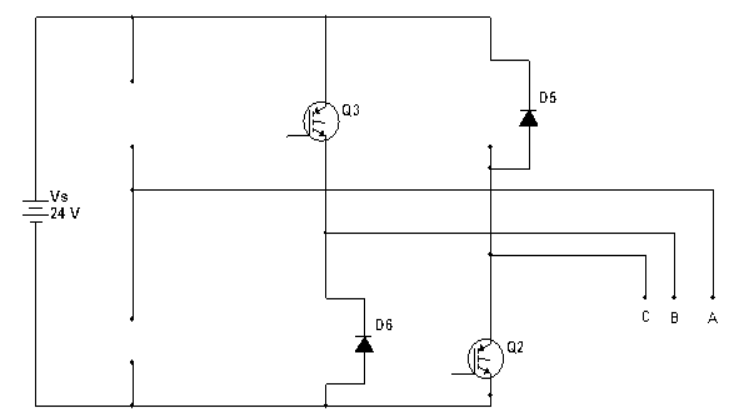

Figure 9 (b).Inverter Switches for Mode 5

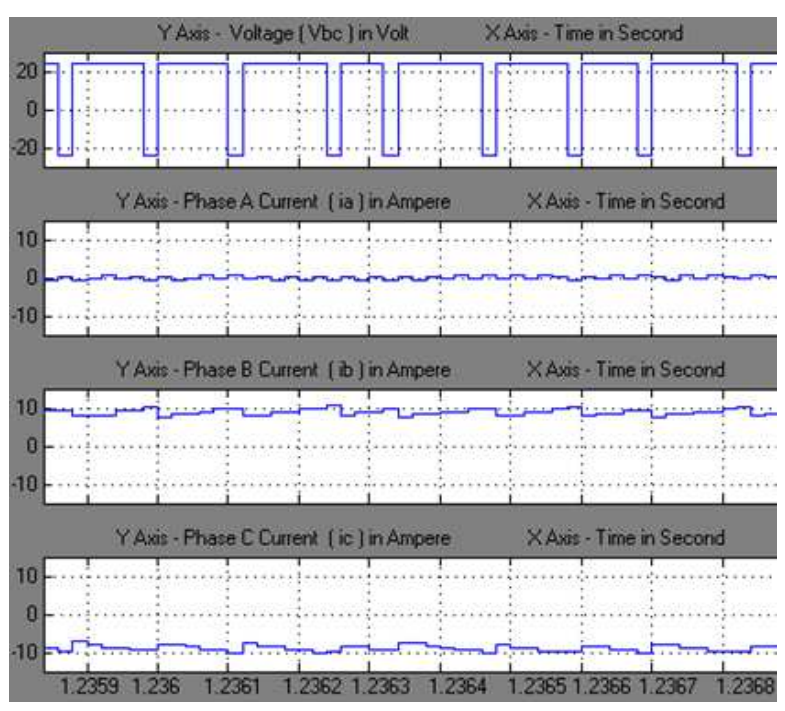

Figure 9 (c). Voltage (Vbc) and current waveform (ia, ib, ic)

Mode 6: This mode corresponds to the hall sensor signal $\left[\begin{array}{lll}1 & 1 & 0\end{array}\right]$. In this, Phase $A$ and Phase $C$ will conduct while Phase B will be off. The IGBT switches [Q1 and Q2] will be on when the hysteresis controller will give switching commands and when the IGBT switches are off then the current will find alternate path through diode (D4 and D5).The line voltage $\mathrm{Vac}=+24$. The results can be observed from figure 10 (a), 10 (b) and 10 (c).

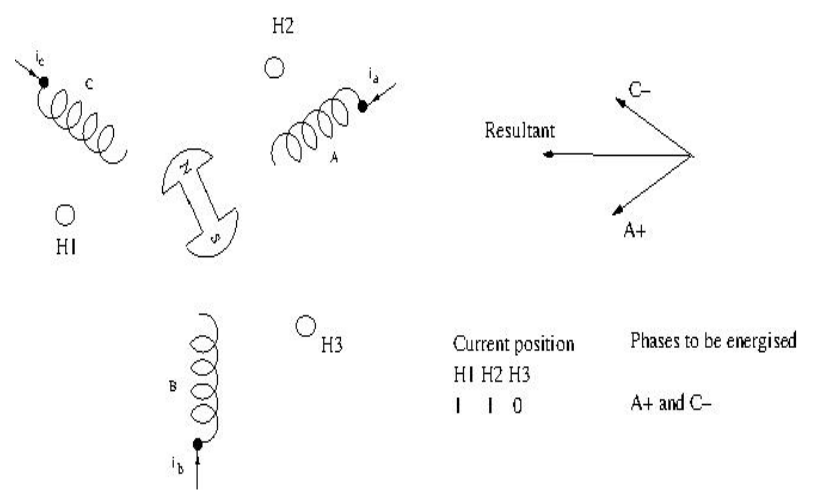

Figure 10 (a).Rotor and Stator Magnetic Field Position in Mode 6

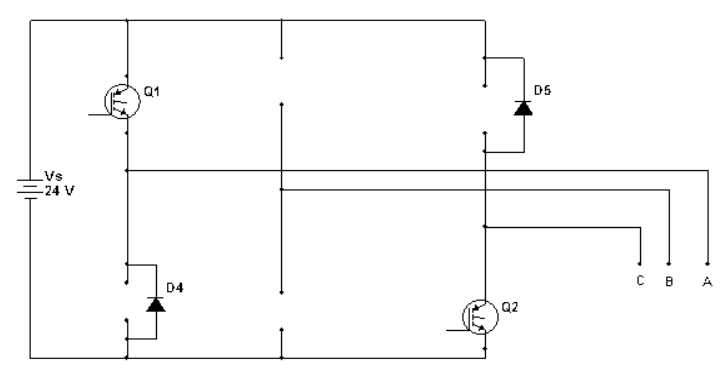

Figure 10 (b).Inverter Switches for Mode 6

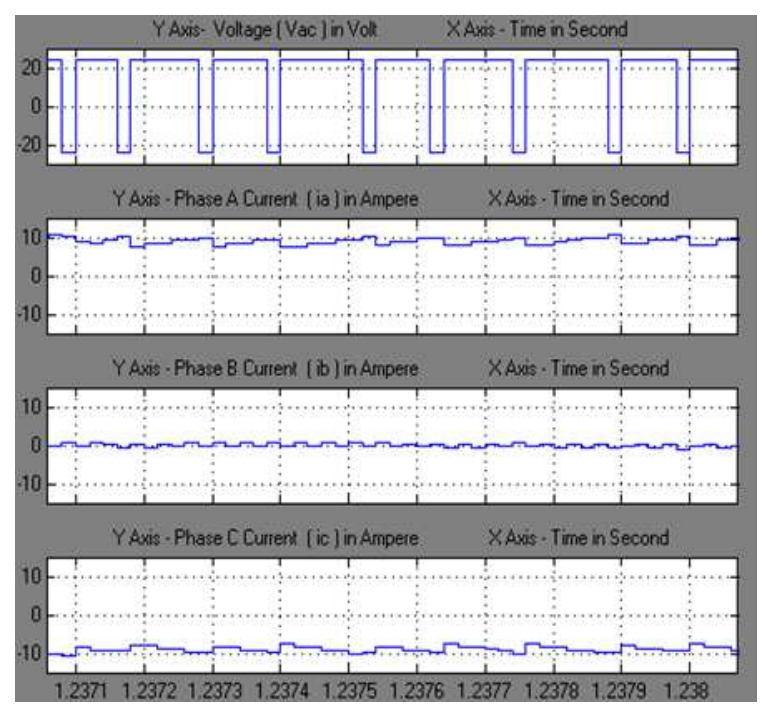

Figure 10 (c). Voltage (Vac) and current waveform (ia, ib, ic)

\section{Simulation Results for BLDC Motor Drive}

The simulink model developed as per block diagram shown in figure 2 was run to verify the algorithm for speed control. The reference speed was changed and rotor speed was recorded and shown here in figure 11 and figure 12. Load torque was also changed and the rotor speed is shown for increase of load in figure 13 and for decrease of load in fig. 14. It is observed that the BLDC motor is following the reference speed. When the load is changing, transients is coming which is dying down in milliseconds. 


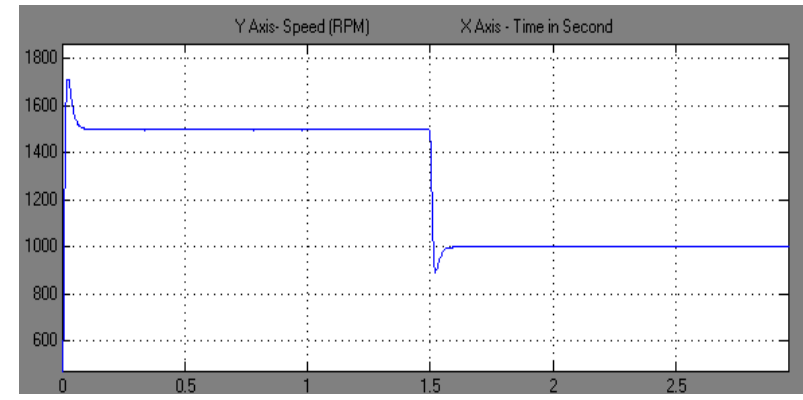

Figure 11. Speed decreased at $1.5 \mathrm{sec}$ from 1500 to $1000 \mathrm{rpm}$

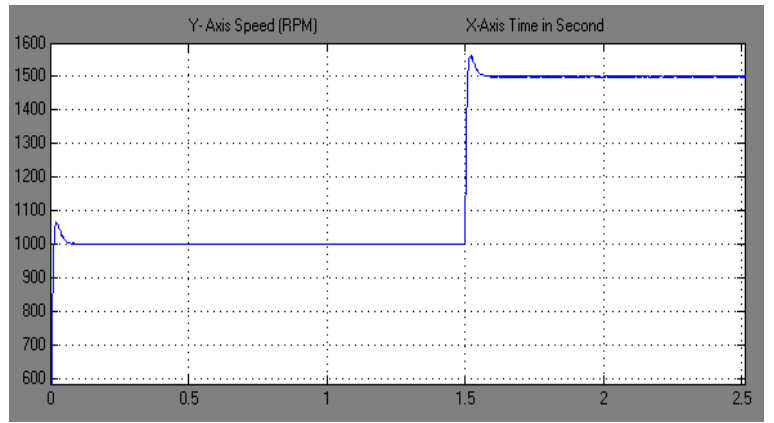

Figure 12. Speed decreased at 1.5sec from 1000 to $1500 \mathrm{rpm}$

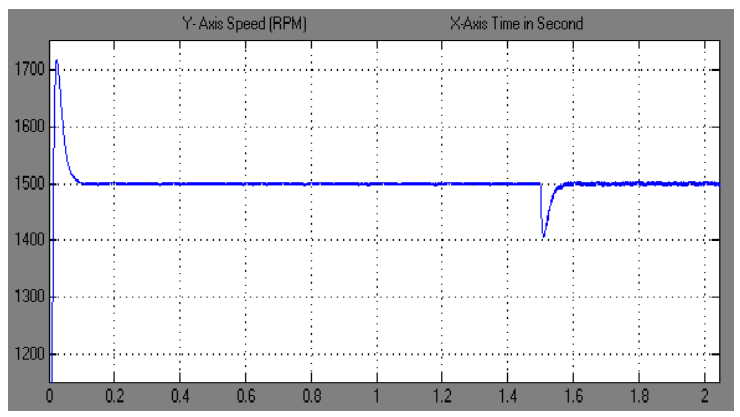

Figure 13. Load Torque increased at $1.5 \mathrm{sec}$ from $30 \%$ to $50 \%$

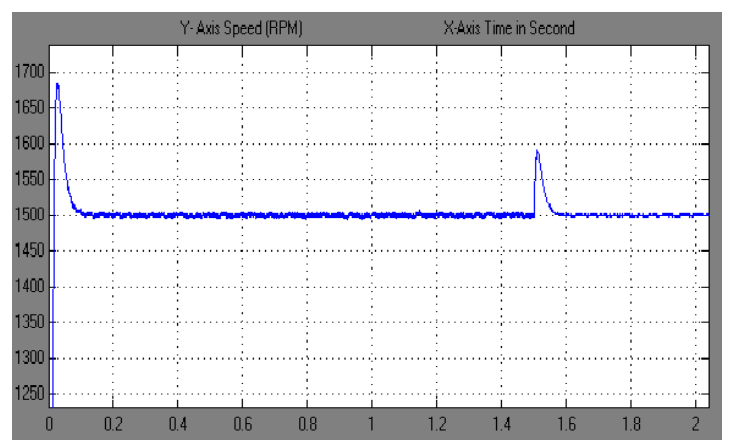

Figure 13. Load Torque decreased at $1.5 \mathrm{sec}$ from $50 \%$ to $30 \%$

\section{Conclusion}

The modeling and digital simulation of BLDC motor drive system has been presented in the paper. A complete analysis of operation of BLDC motor has also been reported in the paper. It can be observed that the switchings of the IGBT switches are in such a way so as to make rotor rotating as per command given by the programmer.
Simulation results confirm that the BLDC motor is following the commands given by the programmer. Different modes discussed above gives a better understanding of the working of the proposed hysteresis band PWM operated BLDC motor drives.

\section{Acknowledgements}

This work was funded completely by National Institute of Ocean Technology (NIOT), Ministry of Earth Sciences, Govt. of India. The authors are grateful to the Director, NIOT and Project Director, Marine Sensor System group for providing all facilities for completion of the project. The authors are also grateful to Dr. T.K Bhattacharya, Professor Department of Electrical Engineering, IIT Kharagpur for his support and ideas which were very helpful in understanding of the topic.

\section{References}

[1] K.Venkatratnam, "Special Electrical Machines", Universities Press India Pvt. Ltd. 2009.

[2] T.J.E. Miller, "Brushless Permanent Magnet \& Reluctance Motor Drives", Clarendon Press, Oxford, Vol.2, 1989

[3] B.K.Bose, "Power Electronics and Motor Drives Advances and Trends", Elsevier Press, Oxford, 2006

[4] R. Krishnan, "Permanent magnet synchronous and brushless DC motor drives", Taylor and Francis, 2010.

[5] Duane Hanselman, "Brushless motors: magnetic design, performance, and control of brushless dc and permanent magnet synchronous motors", E-Man Press LLC , 2012.

[6] Gopal K Dubey "Fundamentals of Electrical Drives", Narosa Publishing House, New Delhi, Second Edn, 2001, Chapter 7, pp271-277.

[7] P.S.Bimbhra "Generalised Theory of Electrical Machines", Khanna Publishers, $5^{\text {th }}$ Edition, 2011.

[8] R. Krishnan, "Electric motor drives- modeling, analysis and control", Prentice Hall, 1st Edition, 2001.

[9] P. Pillay, R. Krishnan, "Modeling, simulation, and analysis of permanent- magnet motor drives, part-I: the brushless DC motor drive", IEEE Transaction on Industry Applications, Vol 25 no.2, 1989, pp 265-273.

[10] P. Pillay, R. Krishnan, "Modeling, simulation, and analysis of permanent- magnet motor drives, part-II: the brushless DC motor drive", IEEE Transaction on Industry Applications, Vol 25 no.2, 1989, pp 274-279.

[11] Chang- Liang Xia, "Permanent Magnet Brushless DC Motor Drives and Controls", Wiley Science Press, 1st Edition, 2012.

[12] M. Lajoie-Mazenc, C. Villanueva, and J. Hector, "Study and implementation of a hysteresis controlled inverter on a permanent magnet synchronous machine" IEEE Transaction on Industrial Applications, Vol. IA-21 No.2, 1985, pp 408413. 
[13] A.K.Singh and K.Kumar, "Modeling and Simulation of PID Controller Type PMBLDC Motor", Proceedings of National Seminar on Infrastructure Development Retrospect and prospects, Vol. I, Institution of Engineers (I), (India),2002, pp. 137-146.

[14] J. W. Dixon and I. A. Leal, "Current control strategy for brushless dc motors based on a common dc signal," IEEE Trans. Power. Electron., vol. 17, no. 2, March 2002, pp. 232240.

[15] U. Vinatha, S. Pola, and K.P. Vittal, "Simulation of Four

\section{Biography}

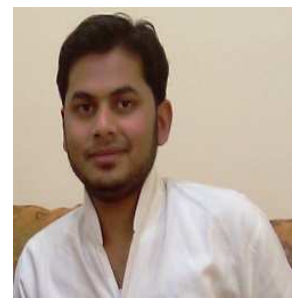

Mohd Tariq belongs to Allahabad. He completed B.Tech from AMU in 2011 and M.Tech from IIT Kharagpur in 2013.

He worked as a Scientist at NIOT, Chennai wherein he was involved in many projects which includes the design of high speed underwater BLDC motor with controllers, design of portable power supply for buried object scanning sonar (BOSS) etc. to name few. Presently he is working as a faculty at MANIT, Bhopal (An Institute of National Importance). He has published several research papers in indexed international journals. His research interests include power electronics, electrical motor drives \& renewable energy.
Quadrant Operation \& Speed Control of BLDC Motor on MATLAB/ SIMULINK," IEEE TECON, 2008, pp. 1-6.

[16] Ward Brown, "Brushless DC Motor Control Made Easy, AN857”, Microchip, 2002.

[17] Brushless DC Motor Control using the LPC2141 Application Note; AN10661, NXP Semiconductors: Eindhoven, the Netherlands, October 2007.

[18] M S Jamil Asghar, “ Power Electronics” , Prentice Hall India , 1st Edition 2004.

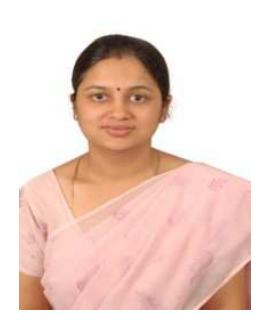

Nidhi Varshney belongs to Dehradun, India. She received her B.E degree in Electrical Engineering with honors from Bhilai Institute of Technology in 2001. She pursued her M.Tech in Control Systems from National Institute of Technology Kurukshetra in 2003.

She has been working as a scientist in National Institute of Ocean Technology (NIOT) since 2009. Before that she worked as lecturer in an Engineering college. She has also published some papers in International conferences like SYMPOL, UT-13 etc. Her main areas of research are design and development of mathematical \& control model for underwater vehicle. 